\title{
Internal Deformation Monitoring of Slope Based on BOTDR
}

\author{
Yijie Sun, ${ }^{1,2}$ Bin Shi, ${ }^{3}$ Dan Zhang, ${ }^{3}$ Hengjin Tong, ${ }^{4}$ Guangqing Wei, ${ }^{4}$ and Hongzhong Xu ${ }^{1}$ \\ ${ }^{1}$ College of Transportation Science \& Engineering, Nanjing Tech University, Nanjing 210009, China \\ ${ }^{2}$ Key Laboratory of Ministry of Education for Geomechanics and Embankment Engineering, Hohai University, Nanjing 210098, China \\ ${ }^{3}$ School of Earth Sciences and Engineering, Nanjing University, Nanjing 210023, China \\ ${ }^{4}$ Suzhou NanZee Sensing Technology Co., Ltd., Suzhou 215123, China
}

Correspondence should be addressed to Bin Shi; shibin@nju.edu.cn

Received 1 April 2016; Revised 16 June 2016; Accepted 12 July 2016

Academic Editor: Zhenhua Zhu

Copyright (C) 2016 Yijie Sun et al. This is an open access article distributed under the Creative Commons Attribution License, which permits unrestricted use, distribution, and reproduction in any medium, provided the original work is properly cited.

To overcome the shortcomings of conventional slope monitoring methods, this paper presented an in-place inclinometer based on BOTDR (Brillouin Optical Time Domain Reflectometer) which was used to obtain the long-term internal deformation in the slope. The installation process of optical fiber sensors and its measuring principle were introduced. The result of analysis indicated that the error in the measured displacement was proportional to the square of the inclinometer length and the precision of the BOTDR instrument, while it was inversely proportional to the diameter of the inclinometer tube. An actual field slope deformation monitoring case was also introduced. The results show that the BOTDR based inclinometer has a good consistency with the traditional inclinometer. It can effectively access the internal deformation of the slope and help to find the position of potential sliding surface accurately. This technology shows a high reliability and practicality in engineering application that will promote deeper research of slope in the future.

\section{Introduction}

Landslides as abundant phenomena are widespread in many regions of the world. This kind of disaster directly threatens people's lives and causes significant economic losses [1]. However, there is great uncertainty for the occurrence of landslide considering its formative mechanism, induced factors, frequency, time, and consequences. An early warning and forecasting of landslide disaster can be drawn with a monitoring works of understanding of landslide activity condition and failure mechanism according to engineering experience.

Various monitoring methods and sensors have been introduced into the landslide monitoring fields. Advanced space observation technologies, such as GPS, SAR, and InSAR [2-4], are quite suitable for slope surface movement detecting but cannot access the underground sliding information. The internal information of slope can reflect the deformation of geological structures such as lateral displacement, subsidence, and tilt. It helps to find the potential sliding surface which plays an important role in studying the stability and movement of the slope. The traditional mobile and fixed inclinometers are the common internal deformation detecting methods, which have been used in many slopes and achieve good results, such as Zhujiadian in Three Gorges Reservoir, China [5], and Ivancich landslide and Corvara landslide in Dolomites, Italy [6, 7]. However, the traditional mobile inclinometers need manual measurement at each depth which has low efficiency and cannot realize online monitoring, while the fixed inclinometer has the problem of high cost and limited number of monitoring points.

In the past few decades, distributed fiber optic sensing (DFOS) technologies have developed, including Fiber Bragg Grating, Optical Time/Frequency Domain Reflectometry (OTDR/OFDR), Brillouin Optical Time Domain Reflectometry/Analysis (BOTDR/A), and Brillouin Optical Frequency Domain Reflectometry/Analysis [8, 9]. DFOS technologies have advantages of distributed sensing, high precision, long distance and term, online monitoring, and easiness of installing sensors and building sensing networks which shows great potentialities in the field of geoengineering [1012]. 
Recently some researchers have begun to advocate this technology into the slope monitoring. Pei et al. [13], Ma and Yao [14], Zhang et al. [15], and Wang et al. [16] proposed FBG based in-place inclinometer and Zeni et al. [17] developed BOTDA based in-place inclinometer, which overcomes the disadvantages of conventional inclinometer including electromagnetic interference, gravity dependence, poor durability and stability, and signal loss for long distance transmission. However, FBG is a quasi-distributed technology which may affect the position accuracy of the sliding surface. BOTDA system needs a loop setup which is not convenient in engineering application. In the authors' early study [18], a multifield sensing system based on DFOS technologies was introduced and its monitoring results of a real landslide in Three Gorges Reservoir, China, were analyzed. However, the details about the deformation monitoring method were not further discussed. This paper explained the details about the novel in-place inclinometer based on BOTDR which is a full-distributed and single-end detecting technology. Its measurement principle as well as the error was further discussed. A few new sensing data were collected to compare with the monitoring result of the traditional inclinometer, which verified the reliability and practicality of this method in determining the position of the sliding surface and its deformation.

\section{Internal Deformation Monitoring of Slope Based on BOTDR}

2.1. Principle of BOTDR. The measurement principle of BOTDR is that when a laser pulse is launched into an optical fiber some Brillouin scattered light will come back to the input end for measurement and interpretation. The Brillouin scattered light is caused by nonlinear interaction between the incident light and photons excited within the light propagation medium. This scattered light will change in frequency by a Brillouin shift $\nu_{B}(\varepsilon, T)$. It has been found that there is a relationship between Brillouin frequency shift (BFS) $\nu_{B}(\varepsilon, T)$ and temperature $T$ or strain $\varepsilon$; the relationship can be expressed as follows [19,20]:

$$
\nu_{B}(\varepsilon, T)=\nu_{B}\left(0, T_{0}\right)+C_{1} \varepsilon+C_{2}\left(T-T_{0}\right),
$$

where $\nu_{B}(\varepsilon, T)$ is Brillouin scattered frequency shift with strain at a certain temperature $T, \nu_{B}\left(0, T_{0}\right)$ is Brillouin scattered frequency shift without strain at temperature $T_{0}$, $C_{1}$ and $C_{2}$ are, respectively, the strain coefficient and the temperature coefficient, and $T_{0}$ is the initial temperature.

2.2. Principle of BOTDR Based Inclinometer. Figure 1 is a schematic diagram of BOTDR based inclinometer. It consists of two parts, test tube and strain sensing fiber. Specifically, four optical fibers are installed on the surface of the test tube at four positions orthogonal to each other. The tube can be made of metal, plastic (PPR, PVC, etc.), and other materials which just depends on the engineering conditions. Based on the classic Euler beam theory, the lateral displacement of the tube can be calculated with optical fiber strain data.

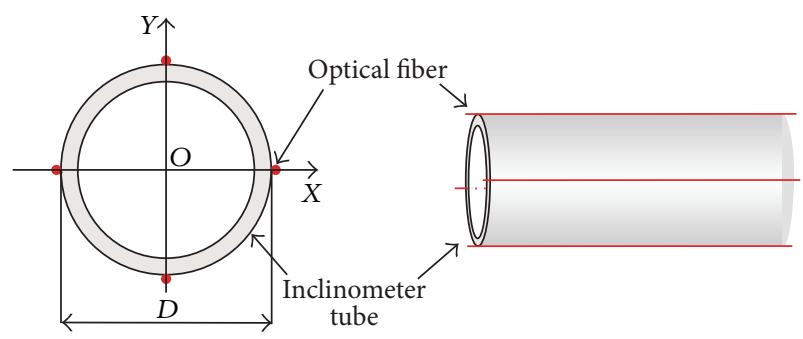

FIGURE 1: BOTDR based inclinometer.

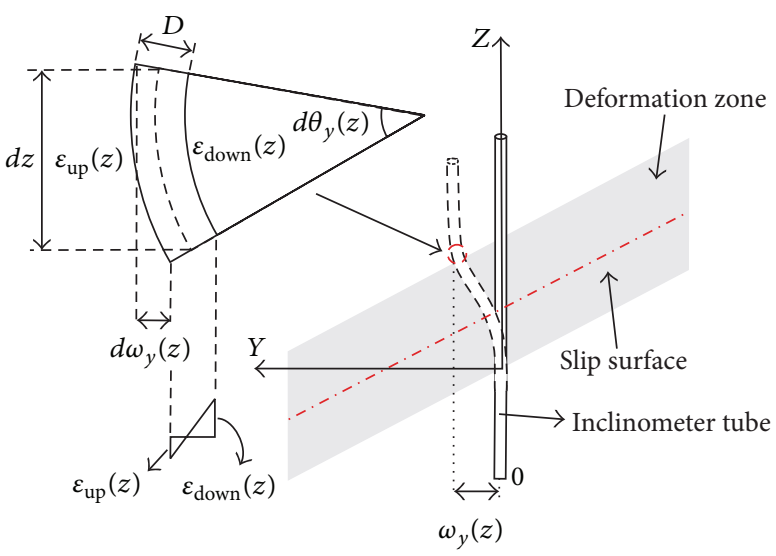

FIGURE 2: Principle of displacement calculation.

As shown in Figure 2, the relationships between the bending displacement, rotation angle, and the strain of tube can be expressed as [13, 21]:

$$
\begin{aligned}
& \omega(z)=\int d \theta(z) d z+b, \\
& \theta(z)=\int \frac{\varepsilon_{\text {up }}(z)}{D / 2} d z+a=\int \frac{-\varepsilon_{\text {down }}(z)}{D / 2} d z+a,
\end{aligned}
$$

where $\omega(z)$ and $\theta(z)$ are the bending displacement and the rotation angle at location $z \cdot d \theta(z)$ is the differential of $\theta(z)$, and $d \omega(z)$ is the differential of $\omega(z) . \varepsilon_{\text {up }}(z)$ and $\varepsilon_{\text {down }}(z)$ are the strain value on the upper and lower surface of the tube in the bending direction $Y$ and $D$ is the outer diameter of the tube.

Considering that the change of temperature will influence the strain as shown in Formula (1), the monitored fiber optic strain values of the upper and lower surface of the tube $\overline{\varepsilon_{\text {up }}(z)}$ and $\overline{\varepsilon_{\text {down }}(z)}$ are different from the real strain values $\varepsilon_{\text {up }}(z)$ and $\varepsilon_{\text {down }}(z)$. Their relationship can be expressed as

$$
\begin{gathered}
\overline{\varepsilon_{\text {up }}(z)}=\varepsilon_{\text {up }}(z)+\Delta \varepsilon_{T}(z), \\
\overline{\varepsilon_{\text {down }}(z)}=\varepsilon_{\text {down }}(z)+\Delta \varepsilon_{T}(z),
\end{gathered}
$$

where $\Delta \varepsilon_{T}(z)$ is the effect of temperature on strain. In the paper of Ma and Yao [14], it was obtained indirectly by measuring the temperature with thermometer which may be 
inconvenient or even unrealistic in the actual project. Here, $\Delta \varepsilon_{T}(z)$ will be eliminated, solving (4):

$$
\varepsilon_{\text {up }}(z)-\varepsilon_{\text {down }}(z)=\overline{\varepsilon_{\text {up }}(z)}-\overline{\varepsilon_{\text {down }}(z)} .
$$

Solving (3) and (5),

$$
\begin{aligned}
\theta(z) & =\int \frac{\varepsilon_{\text {up }}(z)-\varepsilon_{\text {down }}(z)}{D} d z+a \\
& =\int \frac{\overline{\varepsilon_{\text {up }}(z)}-\overline{\varepsilon_{\text {down }}(z)}}{D} d z+a .
\end{aligned}
$$

Substituting (6) into (2),

$$
\omega(z)=\int_{0}^{z} \int_{0}^{z} \frac{\overline{\varepsilon_{\mathrm{up}}(z)}-\overline{\varepsilon_{\mathrm{down}}(z)}}{D} d z d z+a z+b .
$$

The constants $a$ and $b$ can be determined by considering known or assumed boundary conditions.

2.3. Errors Analysis. Usually, it can be assumed that there is no displacement and rotation angle at the bottom of the tube, considering that bottom of the inclinometer tube is embedded in the bedrock. Therefore, the value of $a$ and $b$ in Formula (7) can be assigned to zero. The bottom of the tube is defined as the coordinate origin (Figure 2), and the position of each monitoring point along the axis of the tube is marked as $z_{i}$; for example, the bottom monitoring point is $z_{1}$, which is equal to zero. Generally, $z_{i}$ can be expressed as

$$
z_{i}=(i-1) h, \quad(i=1 \sim n),
$$

where $n$ is the total number of monitoring points and $h$ is the spatial sampling interval of BOTDR instrument which is equal to the average distance of adjacent measuring points. Formula (7) can be written in a discrete form based on the trapezoidal integration as follows:

$$
\begin{aligned}
& \omega\left(z_{n}\right)=\frac{h^{2}}{4 D}\left[(2 n-3)\left(\overline{\varepsilon_{\text {up }}\left(z_{1}\right)}-\overline{\varepsilon_{\text {down }}\left(z_{1}\right)}\right)\right. \\
& \quad+\overline{\varepsilon_{\text {up }}\left(z_{n}\right)}-\overline{\varepsilon_{\text {down }}\left(z_{n}\right)} \\
& \left.\quad+4 \sum_{i=2}^{n-1}(n-i)\left(\overline{\varepsilon_{\text {up }}\left(z_{i}\right)}-\overline{\varepsilon_{\text {down }}\left(z_{i}\right)}\right)\right], \quad(i=1 \sim n),
\end{aligned}
$$

where $\overline{\varepsilon_{\text {up }}\left(z_{i}\right)}$ and $\overline{\varepsilon_{\text {down }}\left(z_{i}\right)}$ are the monitored strains of optical fibers installed on the upper and lower surface of the tube.

The measurement error of $\overline{\varepsilon_{\text {up }}\left(z_{i}\right)}$ and $\overline{\varepsilon_{\text {down }}\left(z_{i}\right)}$ can be assumed to obey normal distribution with standard deviation of $\delta$; according to the principle of measurement error propagation, the error estimation $M_{\omega\left(z_{n}\right)}$ of $\omega\left(z_{n}\right)$ is obtained as

$$
M_{\omega\left(z_{n}\right)}=\frac{(n-1)^{2} h^{2}}{\sqrt{2} D} \delta=\frac{z_{n}^{2}}{\sqrt{2} D} \delta .
$$

Formula (10) indicates that the error of the displacement is proportional to the square of the length and the precision of

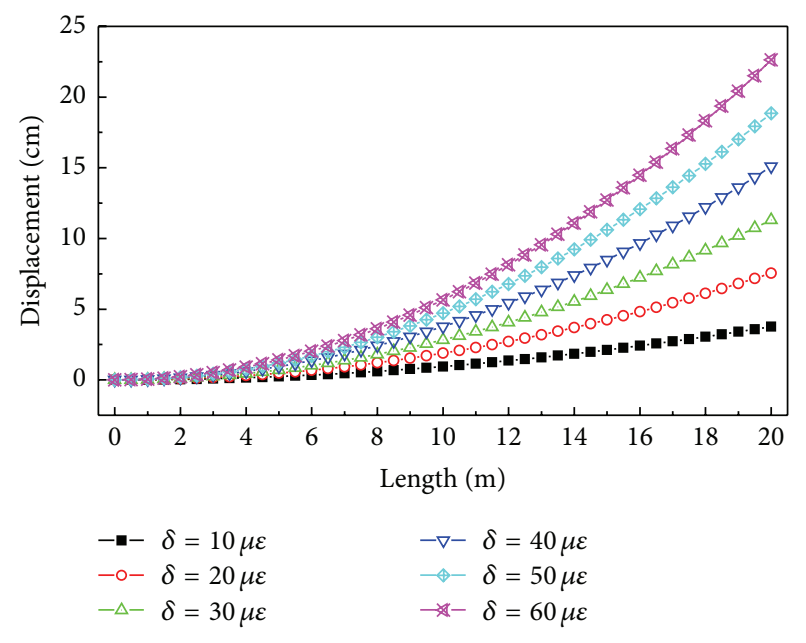

FIGURE 3: Displacement error increases with the length of calculation.

the BOTDR instrument, while it is inversely proportional to the diameter of tube. The error can be effectively reduced by increasing the diameter of the tube, improving the precision of instrument, and decreasing the length of calculation. This indicates that the error is highly sensitive to the length for calculation.

Figure 3 shows the increasing error of calculated displacement with length, in which the diameter of tube is set as $7.5 \mathrm{~cm}$ and $\delta$ are $10 \mu \varepsilon, 20 \mu \varepsilon, 30 \mu \varepsilon, 40 \mu \varepsilon, 50 \mu \varepsilon$, and $60 \mu \varepsilon$, respectively. Generally, $\delta$ of the commercial BOTDR instrument is $40 \mu \varepsilon$. When the length of calculation is shorter than $5 \mathrm{~m}$, the error will be less than $1 \mathrm{~cm}$. The error increases with the length, and, theoretically, it reaches the value as large as $15.8 \mathrm{~cm}$ at the length of $20 \mathrm{~m}$. Therefore, it is difficult to obtain the accurate cumulative displacement that is far away from the bottom of the tube. However, considering that the sliding zone around the sliding surface is usually not very thick (a few meters) and its deformation is much larger than the other parts of landslide bodies, the measurement accuracy of the relative displacement for the sliding surface can be guaranteed. Formula (9) can be used to calculate the cumulative displacement from the bottom to the top of the sliding zone assuming that there is little rotation angle at the bottom of the sliding zone.

\section{Application}

3.1. Introduction of the Project. Block 1 of Majiagou landslide is located in Guizhou town of Zigui County of the Three Gorges Reservoir Area. It lies in the left bank of Zhaxi River with a volume of $127.8 \times 10^{4} \mathrm{~m}^{3}$. The average slope of this landslide is about $15^{\circ}$ and the main sliding direction is $290^{\circ}$. It is mainly composed of talus material and residual deposit with loose structure and strong water permeability. The bedrock is quartz sandstone or fine sandstone mixed with mudstone and a little silty mudstone. To obtain the internal behavior of this landslide, 6 observation boreholes numbered as B1, B2, B3, B4, B5, and B6 for inclinometer 


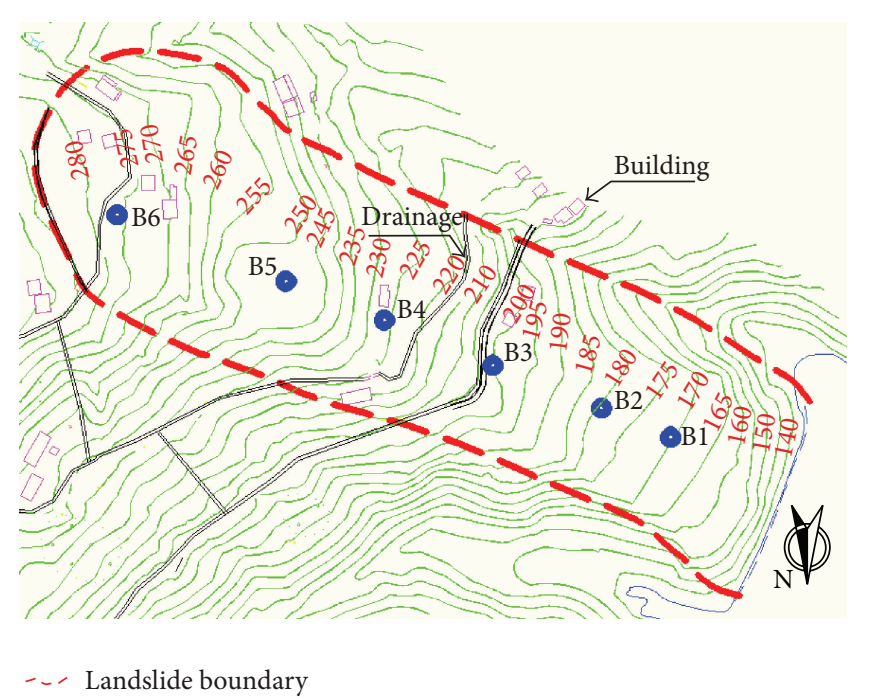

(a)

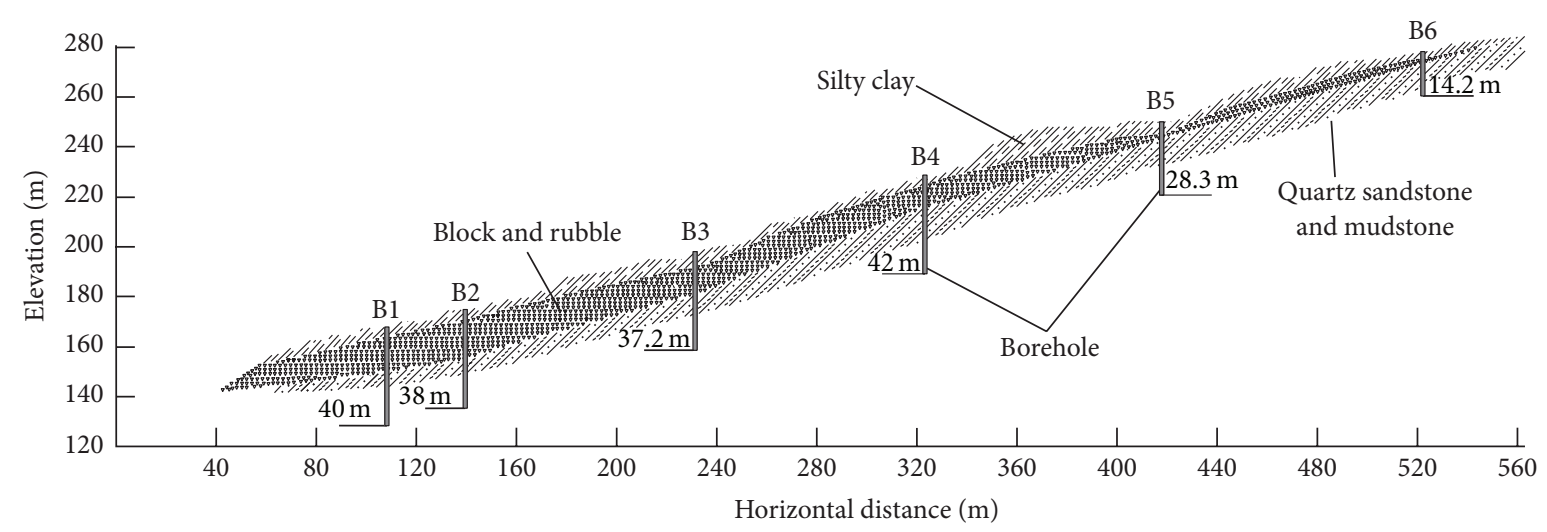

(b)

Figure 4: (a) Topographic map of the slope [18]; (b) engineering geological cross section.

were designed along the main sliding direction at different elevations (Figures 4(a) and 4(b)).

The distributed strain sensing optical fiber supplied by Suzhou NanZee Sensing Ltd., China (type: NZS-DSS-C07), was used on the BOTDR based inclinometer (Figure 5(a)). It consists of a optical fiber core $(250 \mu \mathrm{m})$, an inner polymeric coating $(0.9 \mathrm{~mm})$, and an outer polyurethane sheath $(2 \mathrm{~mm})$. BFS shows a good linear relationship with axial strain change at room temperature $\left(22^{\circ} \mathrm{C}\right)$ in Figure $5(\mathrm{~b})$.

Figure 6 shows the details about the installation process. The monitoring tube is made of aluminum with a diameter of $7.5 \mathrm{~cm}$. Optical fibers were prestressed and then fixed on the surface of the tube with the glue of epoxy resin. After the glue was solidified, the tube was protected with highstrength tape and shrink film material to prevent the fiber from damage during the installation process (Figure 6(b)). In this test, traditional inclinometers were also installed to compare and validate the results measured by the BOTDR based inclinometer tube.

The BOTDR based monitoring system was completed on August 24, 2012. The optical fiber strain data analyzer used in this project is the type N8511 BOTDR produced by ADVANTEST Co. Ltd. of Japan (Figure 7). The data monitored on September 8, 2012, are set as the initial data, which are subtracted from the subsequent monitored data to obtain the variation of the slope internal deformation.

3.2. Monitoring Results and Discussion. Here we take the measurement data of borehole B4 as an example. Figure 8(a) shows the measurement result of traditional inclinometer. It gives the cumulative displacement (compared to the displacement at the bottom) at different depth of the borehole. Figure $8(\mathrm{~b})$ is the flexural strain distribution of the monitoring tube using BOTDR. Both Figures 8(a) and 8(b) indicate two remarkable shear zones at the depth around $12 \mathrm{~m}$ and $35 \mathrm{~m}$ with the thickness around $2 \mathrm{~m}$, which can be inferred as the sliding surfaces. The relative displacement between the upper part and the lower part of the rock and soil around the deep sliding surface can be calculated with the fiber strain data based on the method introduced in Section 2.2. The relative displacement of the sliding zone around the depth of $35 \mathrm{~m}$ is compared with the total cumulative displacement of the slope at the depth of $0 \mathrm{~m}$. The deformation percentage is found to be $67 \%, 64 \%, 74 \%, 72 \%, 77 \%$, and $67 \%$, respectively, at different 


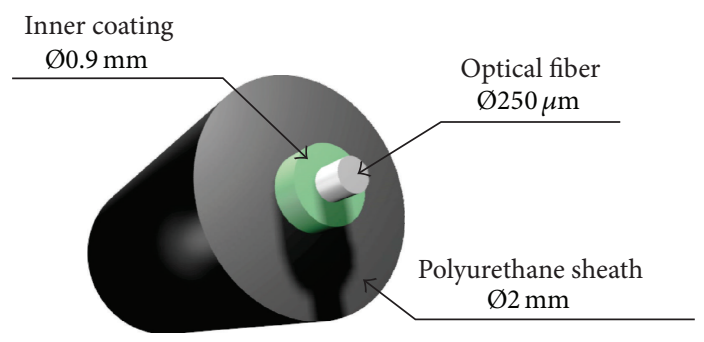

(a)

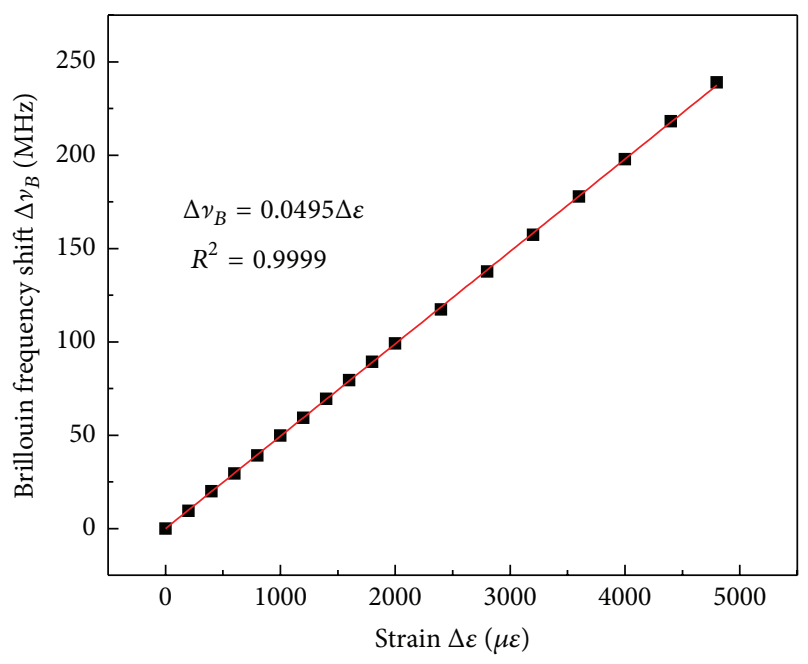

(b)

FIGURE 5: (a) Cross section of the strain sensing optical fiber; (b) relationship between BFS and axial strain.

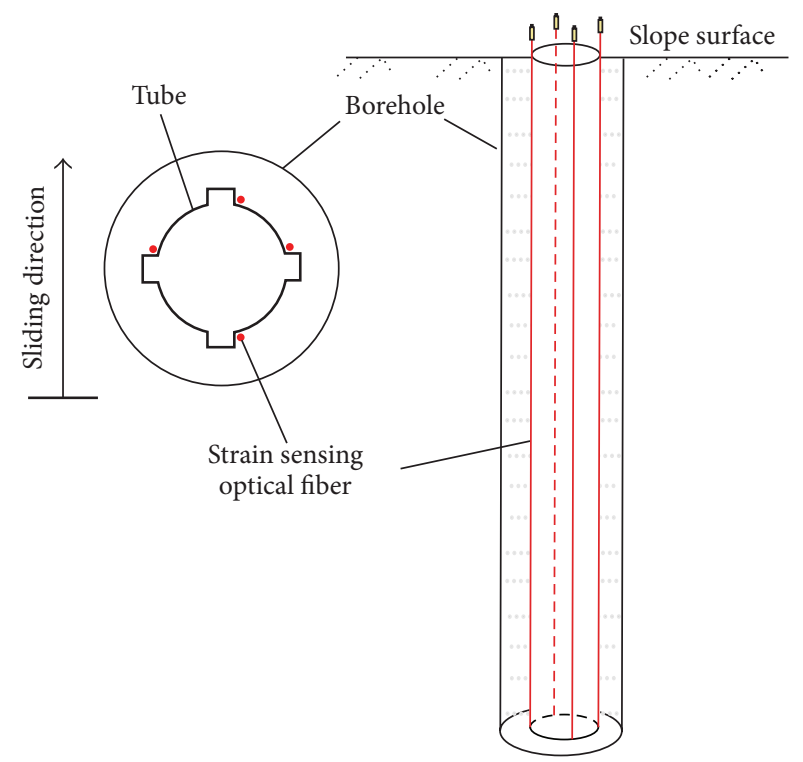

(a)
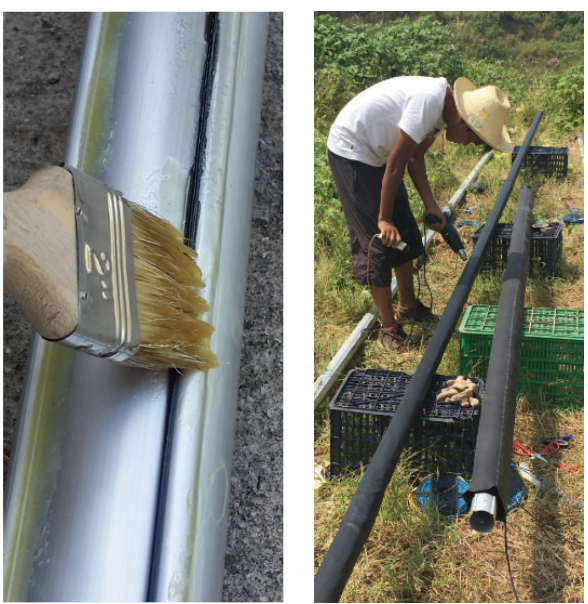

(b)

FIGURE 6: (a) Distribution of sensors in the borehole; (b) installation of BOTDR based inclinometer.

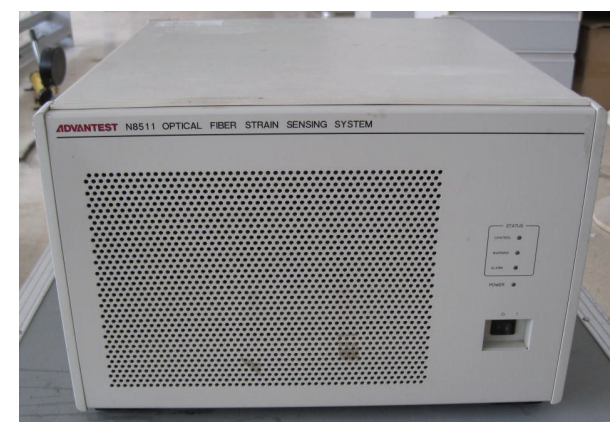

(a)

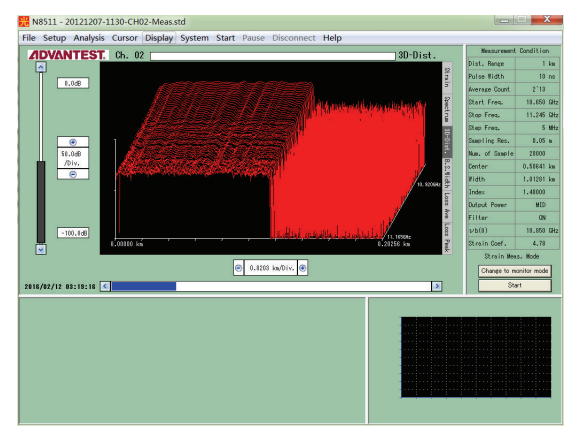

(b)

FIGURE 7: BOTDR instrument: (a) readout unit; (b) software. 


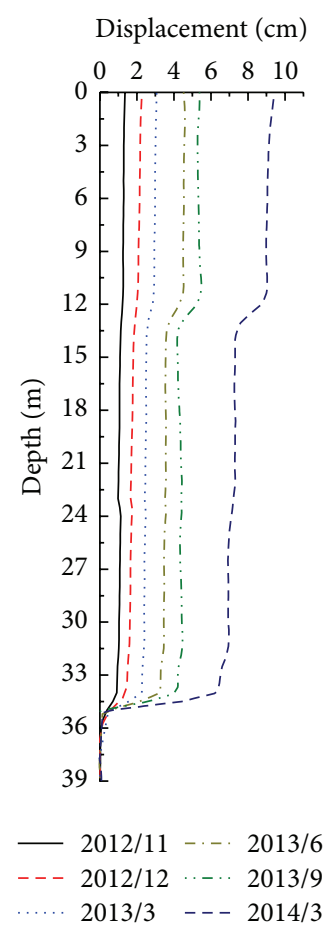

(a)

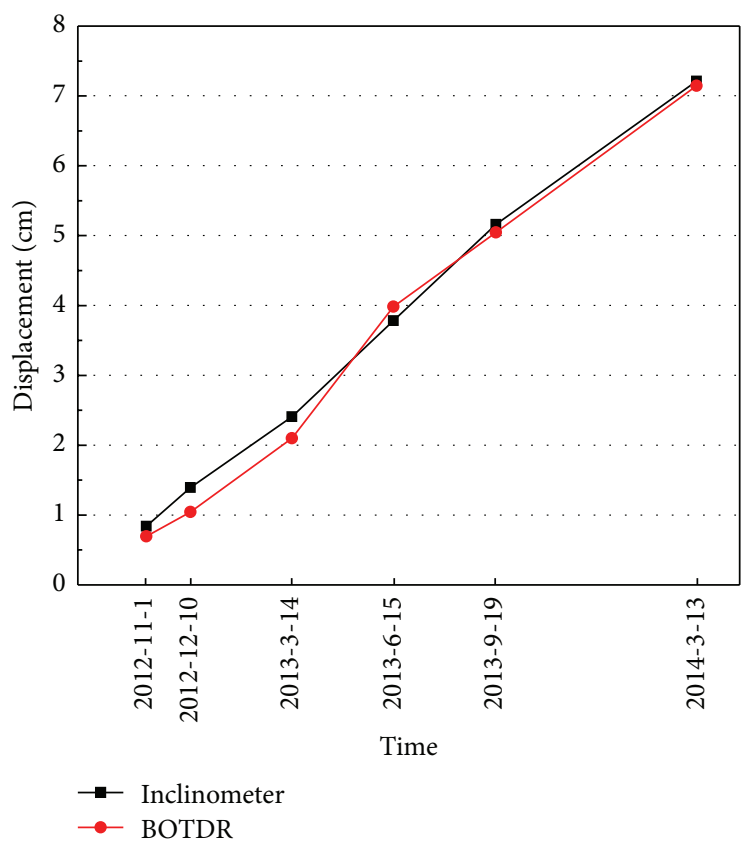

(c)

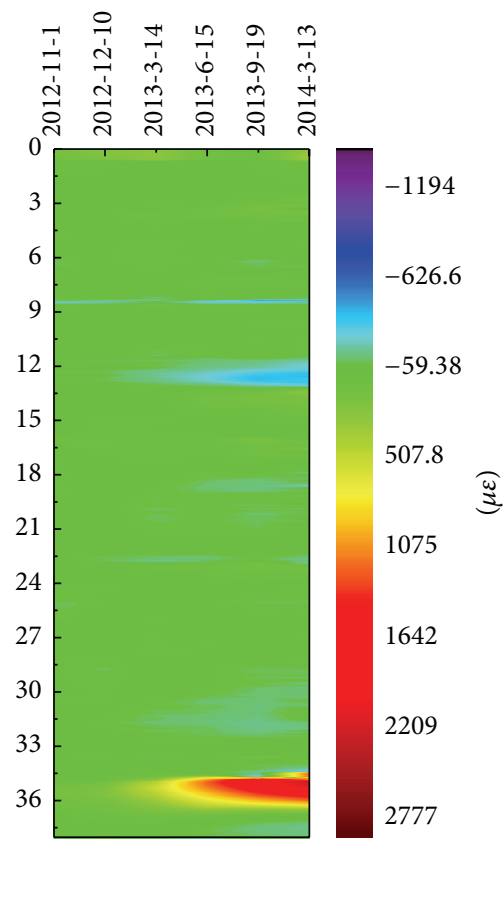

(b)

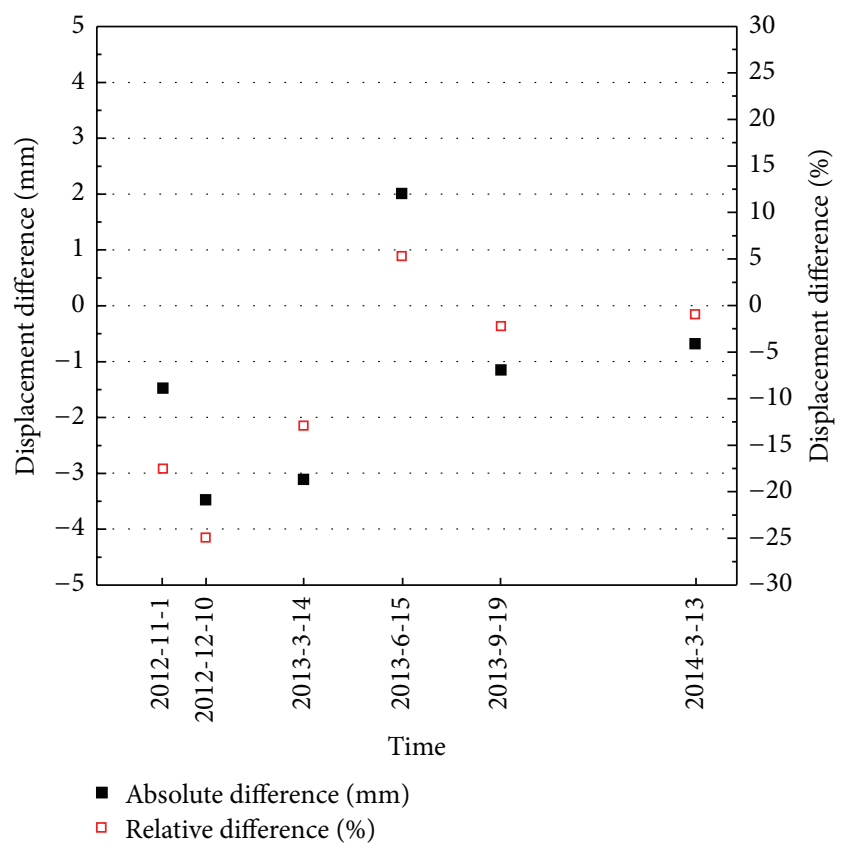

(d)

Figure 8: (a) Cumulative horizontal displacement profiles of borehole B4; (b) space-time distribution of optical fiber strain; (c) relative displacement of sliding surface; (d) displacement difference between inclinometer and BOTDR based method measurement result.

measurement times, indicating that the deformation of this landslide is controlled by this sliding surface.

Figure 8(c) shows the increasing relative displacement of the sliding zone over time. The monitoring result of BOTDR based method is similar with that of traditional inclinometer with the difference less than $4 \mathrm{~mm}$. It shows that the displacement of the sliding surface is around $7 \mathrm{~cm}$ up to
March 2014, which is equal to a deformation rate of $2 \mathrm{~mm}$ per day.

Figure 9 reveals the slope internal deformation after considering the monitoring results from all the observation boreholes. It shows that the Block 1 of Majiagou landslide has two main deep sliding planes, that is, $1-1^{\prime}$ and $2-2^{\prime}$. The first one $1-1^{\prime}$ is at the average depth of about $15 \mathrm{~m}$ and the second 


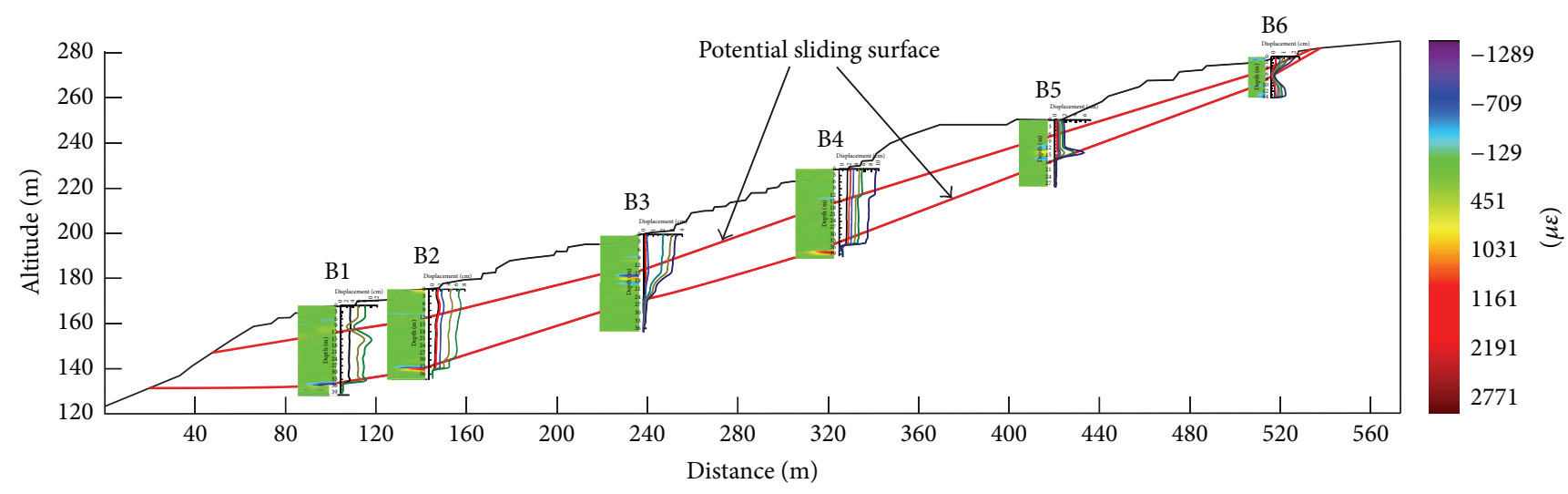

FIGURE 9: Internal deformation monitoring result from all the boreholes.

one $2-2^{\prime}$ is at the average depth of about $34 \mathrm{~m}$. It should be noted that because of the limited numbers of boreholes the distribution mode of sliding planes is potentially not very accurate; however, it is consistent with the overall movement trend of the slope.

\section{Conclusion}

In this study, the author developed a BOTDR inclinometer based on the Euler beam theory, which is a useful supplement for traditional inclinometer. The error analysis results indicate that the inclinometer length, the precision of the BOTDR instrument, and the diameter of tube are the main factors that determine the measurement error. It was installed in a real landslide and successfully identified two slip surfaces. The relative displacement of slip surface and its movement over time was calculated accurately. The data monitored with BOTDR fiber optic sensing technology is consistent with the result of traditional inclinometer for the sliding zone with the difference less than $4 \mathrm{~mm}$, demonstrating its high reliability and applicability. This newly developed technology will have a promising future for landslide monitoring.

\section{Competing Interests}

The authors declare that they have no competing interests.

\section{Acknowledgments}

The authors gratefully acknowledge the financial support provided by the State Key Program of National Natural Science of China (41230636), the State Key Program of National Natural Science of China (41427801), Natural Science Foundation of Jiangsu Province (BK20160997), Key Laboratory of Ministry of Education for Geomechanics and Embankment Engineering, Hohai University (no. 201501), and University Science Research Project of Jiangsu Province (16KJB410001), Qing Lan Project. The authors thank Ebrahim Nazarian for his kind help on this paper.

\section{References}

[1] D. Petley, "Global patterns of loss of life from landslides," Geology, vol. 40, no. 10, pp. 927-930, 2012.

[2] M. Crosetto, B. Crippa, and E. Biescas, "Early detection and indepth analysis of deformation phenomena by radar interferometry," Engineering Geology, vol. 79, no. 1-2, pp. 81-91, 2005.

[3] L. Cascini, G. Fornaro, and D. Peduto, "Advanced low- and fullresolution DInSAR map generation for slow-moving landslide analysis at different scales," Engineering Geology, vol. 112, no. 14, pp. 29-42, 2010.

[4] W. Zhu, Q. Zhang, X. Ding et al., "Landslide monitoring by combining of CR-InSAR and GPS techniques," Advances in Space Research, vol. 53, no. 3, pp. 430-439, 2014.

[5] X. Hu, M. Zhang, M. Sun, K. Huang, and Y. Song, "Deformation characteristics and failure mode of the Zhujiadian landslide in the three gorges Reservoir, China," Bulletin of Engineering Geology and the Environment, vol. 74, no. 1, pp. 1-12, 2013.

[6] F. Calò, F. Ardizzone, R. Castaldo et al., "Enhanced landslide investigations through advanced DInSAR techniques: the Ivancich case study, Assisi, Italy," Remote Sensing of Environment, vol. 142, no. 3, pp. 69-82, 2014.

[7] A. Corsini, A. Pasuto, M. Soldati, and A. Zannoni, "Field monitoring of the Corvara landslide (Dolomites, Italy) and its relevance for hazard assessment," Geomorphology, vol. 66, no. 1-4, pp. 149-165, 2005.

[8] X. Y. Bao and L. Chen, "Recent progress in Brillouin scattering based fiber sensors," Sensors, vol. 11, no. 4, pp. 4152-4187, 2011.

[9] X. Y. Bao and L. Chen, "Recent progress in distributed fiber optic sensors," Sensors, vol. 12, no. 7, pp. 8601-8639, 2012.

[10] L. D. Suits, T. C. Sheahan, L. Olivares et al., "An instrumented flume to investigate the mechanics of rainfall-induced landslides in unsaturated granular soils," Geotechnical Testing Journal, vol. 32, no. 2, pp. 108-118, 2009.

[11] B. Shi, D. Zhang, H.-H. Zhu, and C. Liu, "Application of distributed optical fiber strain measurement into geotechnical engineering monitoring," in Proceedings of the 8th International Workshop on Structural Health Monitoring, pp. 2327-2341, Stanford, Calif, USA, September 2011.

[12] H.-H. Zhu, A. N. L. Ho, J.-H. Yin, H. W. Sun, H.-F. Pei, and C.Y. Hong, "An optical fibre monitoring system for evaluating the 
performance of a soil nailed slope," Smart Structures \& Systems, vol. 9, no. 5, pp. 393-410, 2012.

[13] H.-F. Pei, J.-H. Yin, H.-H. Zhu, C.-Y. Hong, W. Jin, and D.-S. Xu, "Monitoring of lateral displacements of a slope using a series of special fibre Bragg grating-based in-place inclinometers," Measurement Science \& Technology, vol. 23, no. 2, Article ID 025007, 2012.

[14] H. H. Ma and B. B. Yao, "Application of fiber bragg grating sensing technology in slope monitoring," Journal of Highway \& Transportation Research \& Development, vol. 30, no. 10, pp. 28 32, 2013 (Chinese).

[15] H. Zhang, J. J. Wu, and X. M. Huang, "Application of fiber Bragg grating inclinometer to deformation monitoring of geotechnical slope," Journal of Nanchang Institute of Technology, vol. 34, no. 4, pp. 60-65, 2015.

[16] Y. L. Wang, B. Shi, T. L. Zhang, H. H. Zhu, Q. Jie, and Q. Sun, "Introduction to an FBG-based inclinometer and its application to landslide monitoring," Journal of Civil Structural Health Monitoring, vol. 5, no. 5, pp. 645-653, 2015.

[17] L. Zeni, L. Picarelli, B. Avolio et al., "Brillouin optical timedomain analysis for geotechnical monitoring," Journal of Rock Mechanics and Geotechnical Engineering, vol. 7, no. 4, pp. 458462, 2015.

[18] Y.-J. Sun, D. Zhang, B. Shi, H.-J. Tong, G.-Q. Wei, and X. Wang, "Distributed acquisition, characterization and process analysis of multi-field information in slopes," Engineering Geology, vol. 182, pp. 49-62, 2014.

[19] T. Kurashima, T. Horiguchi, H. Izumita, S.-I. Furukawa, and Y. Koyamada, "Brillouin optical-fiber time-domain reflectometry," IEICE Transactions on Communications, vol. 76, no. 4, pp. 382-390, 1993.

[20] X. Y. Bao, J. Dhliwayo, N. Heron, D. J. Webb, and D. A. Jackson, "Experimental and theoretical studies on a distributed temperature sensor based on Brillouin scattering," Journal of Lightwave Technology, vol. 13, no. 7, pp. 1340-1348, 1995.

[21] H. Mohamad, K. Soga, A. Pellew, and P. J. Bennett, "Performance monitoring of a secant-piled wall using distributed fiber optic strain sensing," Journal of Geotechnical \& Geoenvironmental Engineering, vol. 137, no. 12, pp. 1236-1243, 2012. 


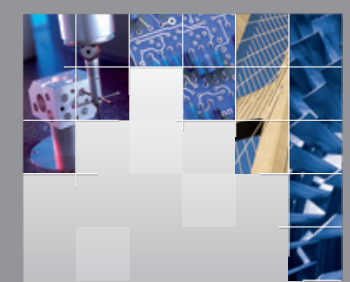

\section{Enfincering}
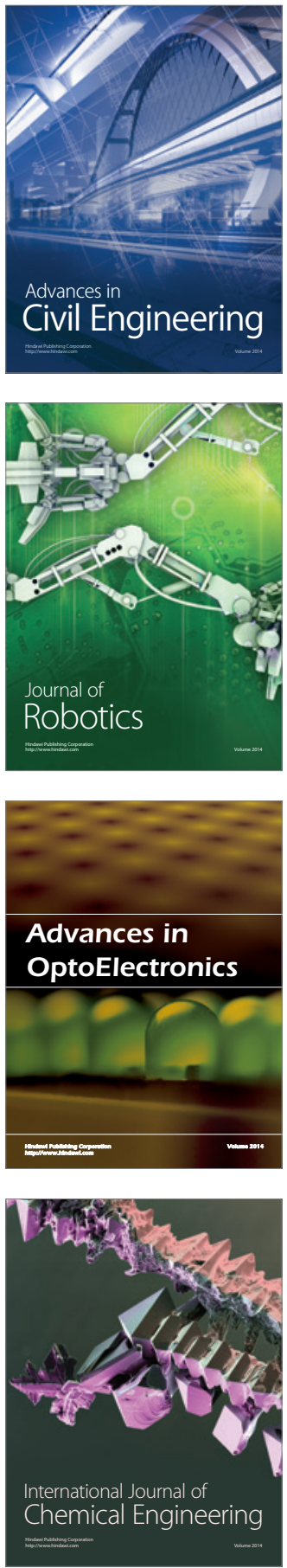

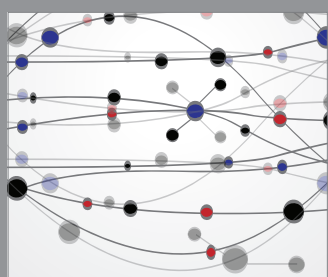

The Scientific World Journal

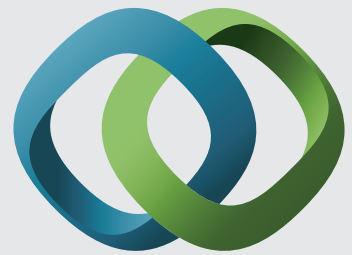

\section{Hindawi}

Submit your manuscripts at

http://www.hindawi.com
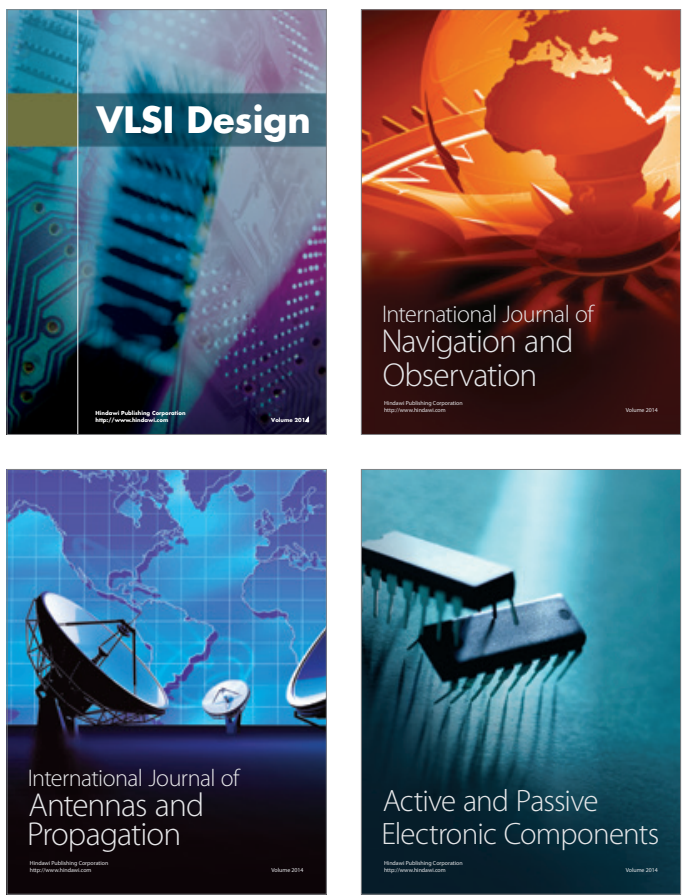
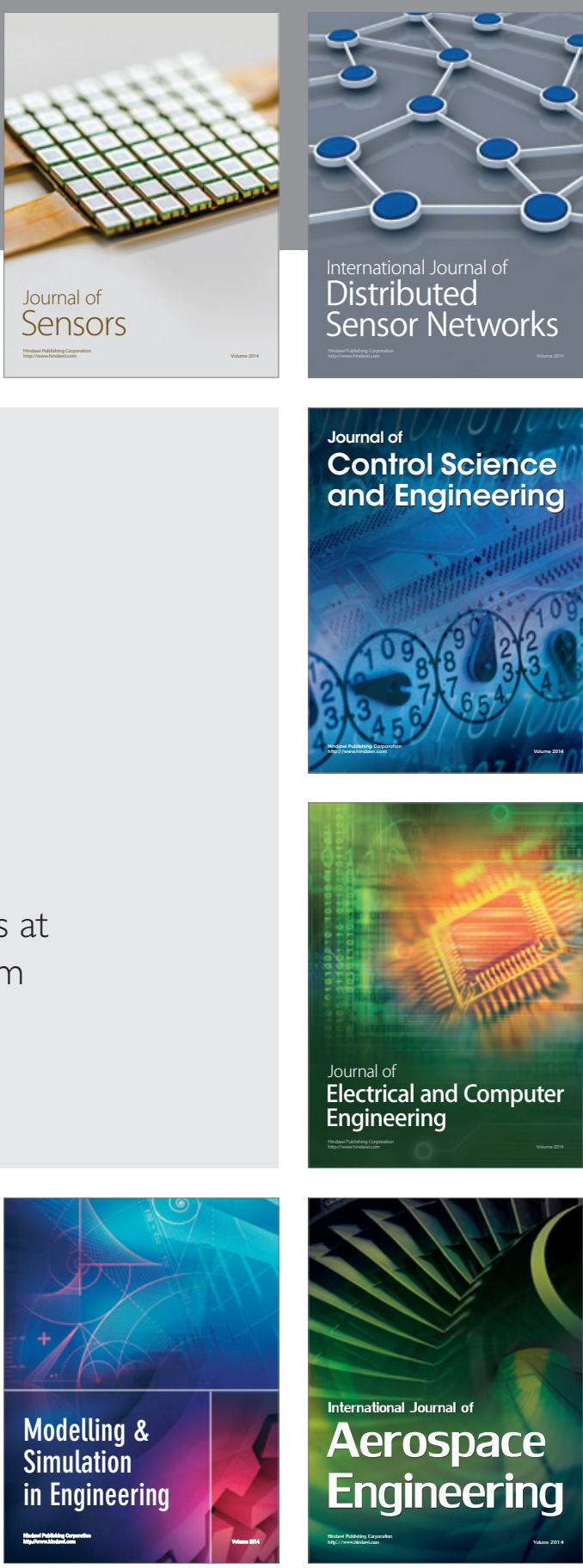

International Journal of

Distributed

Sensor Networks

Journal of

Control Science

and Engineering
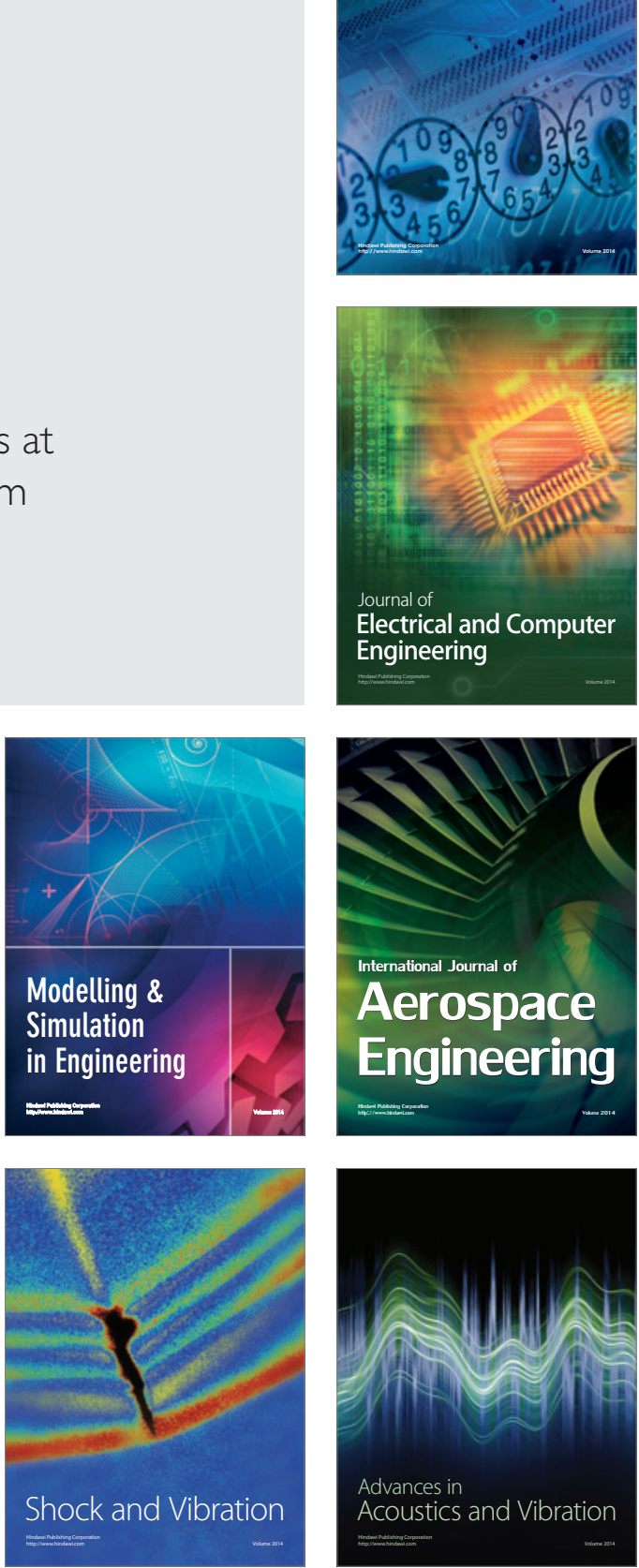